\title{
An Enthymematic Account of the Deduction of the Negative Meaning of the Chinese Shenme-based Rhetorical Question Construction
}

Chengru Dong ${ }^{1}$, Dawei Jin $^{2}$

Soochow University ${ }^{1}$

Shanghai Jiao Tong University ${ }^{2}$

\begin{abstract}
One controversy in the study of the Chinese shenme 'what'-based rhetorical question (shenme-RQ for short) is how it takes on a negative interpretation. This paper attempts to apply enthymeme or rhetorical syllogism to the deduction of negative meaning of the shenme-RQ. Triggered by the shenme-RQ, or one of its words or phrases, the hearer extracts the explicit premise, fills in the premise that is implicit either in the context or in her or his encyclopedic knowledge, and deduces the conclusion, the negative meaning of the shenme-RQ. According to what premises are left out, the paper also explores the deduction patterns of the negative meaning of shenme-RQs and proposes a procedure for obtaining the negative interpretation. That said, the negative meaning of the shenme-RQ will be entrenched in the mind of its users and conventionalized in the Mandarin Chinese community via repeated use.
\end{abstract}

\section{Keywords}

Chinese shenme 'what'-based rhetorical question, negation, enthymeme, conventionalization 


\section{Introduction}

Rhetorical questions are puzzling to scholars of different persuasions, because they have the syntactic form of a question but do not generally demand an answer (i.e., they are not performing an information-seeking speech act) (Sadock 1971, Sadock 1974; Lee-Goldman 2006; Rohde 2006; Ilie 1999, Ilie 2009, inter alia). Rather, a rhetorical question has the illocutionary force of an assertion of the opposite polarity from what is apparently asked (Han 2002).

In Mandarin Chinese, shenme 'what'-based questions can have a rhetorical use. Take the following utterance as an illustration:

(1) Ni nianji hai zheme xiao, shang shenme xue? you age still so young go what school 'You are still so young, what school do you go to?' (Intended: You should not go to school.)

In example (1), although the shenme-clause is formally an interrogative, it requires no answer, and, in Mandarin, feels "semantically equivalent" to the negative declarative clause "Don't (you) go to school!" In the following, we label a shenmeinterrogative in its rhetorical use as the shenme-rhetorical question construction (abbreviated as the shenme-RQ). ${ }^{1}$

Compared with other wh-word-based rhetorical questions, the shenme-RQ construction has attracted a lot of attention because of its syntactic and semantic idiosyncrasies (Lü 1985; Shao and Zhao 1989; Li 1990; Shou 2002; Wang 2003; Yin 2009; Tsai 2011; Wu 2011; Zhu 2013, Zhu 2014; Pan 2014; Yang 2014; Yuan and Liu 2016; Wang 2017; Yang and Tsai 2019). In this paper, we do not deal with syntactic issues of the shenme-RQ but focus on its meaning aspects. The diverse pragmatic forces of shenme-RQs, such as retort, prohibition, dissuasion, accusation, refutation, denial, disapproval, whining, blaming, and so on (Shao 1996; Pan 2014; Yang 2014; Yang and Tsai 2019), can all be boiled down to negation. The problem is how the negative meaning of shenme-RQs comes about. We aim to sketch out a cognitive account of how shenme-RQs, upon utterance, are inferred as not an information request (requiring answers) but rather as a speech act "semantically equivalent" to a declarative construction of the opposite polarity. The remainder of this paper is structured as follows. Section 2 reviews previous accounts on rhetorical questions in general and on Chinese shenme-RQs in particular, summarizing

1 We exclude the "shenme+X not X" structure from our study because its negative meaning is fully conventionalized and we are not sure whether it is a true rhetorical question. According to Lü (1985), this structure was first preceded by bushuo 'not say', then, the negative particle bu 'not' was dropped; later, shuo 'say' was also dropped. The structure has now taken on the meaning of not caring whether it is X or not. Interested readers can refer to Lü (1985: 146-147), Shao and Zhao (1989), and Shao (1996: 240-241) for specific examples. Moreover, we are not concerned with whether shenme is an argument or adjunct of the verb in a rhetorical question. 
the individual merits of different approaches while exposing the shortcomings they face. Section 3 presents the enthymematic theoretical framework of our analysis. Section 4 applies enthymeme to the deduction of the negative meaning of shenme-RQs. Section 5 explores the enthymematic patterns of the deduction of the negative meaning of shenme-RQs and proposes a procedure for deducing the negative meaning of shenme-RQs. Section 6 discusses the entrenchment and conventionalization of the negative meaning of shenme-RQs. The last section concludes the paper.

\section{Previous studies}

Broadly speaking, three kinds of approaches have been offered to deal with the negative meaning of shenme-RQs. One approach argues that shenme-RQs are negative assertions because the question word shenme 'what' expresses some form of negation. Another approach contends that they are actually interrogatives without any true answer. The third approach claims that the whole shenmeRQ construction carries the meaning of negation. We will briefly review each approach in turn.

2.1 The negative meaning of shenme-RQs is contributed by the interrogative shenme 'what': A negative-shenme approach

The first approach states that the locus of shenme-RQs' negativity is on the wh-word shenme 'what'. Specifically, Lü (2005 [1980]: 484-485) endorses this approach, claiming that shenme expresses the negative meaning (see also Li 1990; Shao and Zhao 1989; Shao 1996; Shou 2002; Yuan and Liu 2016). Jiang and Shi (2008) argue that shenme is a negative marker. Wang (2017) also holds that shenme is a negative deontic modal.

The above view is similar to a general theory that attributes the negative polarity meaning of all rhetorical question constructions to wh-words (Sadock 1971, Sadock 1974; Progovac 1993; Han 2002; Sprouse 2007). The most explicit account is developed by Han (2002), who proposes that the wh-word in rhetorical questions maps to a negative quantifier that undergoes quantifier raising in a postLF derivation. Under the quantifier-raising mechanism, the negative quantifier takes scope over the entire propositional content of the rhetorical questions and thus the rhetorical questions take on the negative interpretation.

This approach, as it stands, faces several challenges. The first issue is the implausibility of assuming that shenme in Chinese can be mapped to a negative quantifier. This is because Chinese, unlike English, does not allow negation to be encoded by a negative word without a licensor. Instead, negation is expressed by the licensing of a polarity item in the argument position by an explicit negative operator (i.e., Chinese is not an I like nothing language but an I do not like anything language). Given the general absence of a negative argument phrase such as nothing, it is unclear how Chinese allows a wh-phrase in the argument position to be interpreted as a negative quantifier. 
Another potential problem for the explanation that negation meaning is built into a $w h$-phrase in rhetorical questions is that they are not restricted to $w h$-interrogative constructions. For example, the following yes-no question can receive a rhetorical interpretation under certain contexts: ${ }^{2}$

(2) (A mother is worried about her daughter being taken away by human traffickers, and the daughter replies with the following)

Wo you name youzhi ma?

I have so naïve PRT

(renjia jiechi wo, wo bu hui han jiu ming?)

(people hijack me I NEG can cry save life)

'Am I so naive? (Couldn't I cry for help if people hijacked me?)'

(Abridged from Huang Beijia, I want to be a good child)

If negation is built into a $w h$-word, then we need to explain where the negative assertion comes from for the rhetorical question in example (2) above. One might say that a covert negative operator is responsible for the negative meaning in the yes-no rhetorical question construction. Han (2002) does argue that a yes-no question contains an implicit wh-word that corresponds to whether on the ground of the obligatory use of whether in English indirect yes-no questions. Nevertheless, it remains doubtful whether the Mandarin yes-no question in example (2), headed by the question typing operator $m a$, should be characterized as involving a whether-operator. A commonly held view maintains that the Mandarin equivalent of a whether-question is an A-not-A question, which constructionally encodes the yes-no alternative semantics by the reduplication of the predicate. Example (3) illustrates a direct (matrix) A-not-A question, as well as an indirect A-not-A question.

a. Ni you-mei-you name youzhi? you have-NEG-have so naïve 'Are you so naïve?'

b. Wo xiang zhidao ni you-mei-you name youzhi. I want to know you have-NEG-have so naïve 'I wonder whether you are so naïve.'

Although one may argue that a whether-operator resides where the reduplicative predicate is, a similar argument is less plausible for a $m a$-question, as $m a$-questions fail to be embedded, such that an indirect yes-no question expressed with the $m a-$ operator is unacceptable.

2 The abbreviations used in this paper are as follows: ASP: aspectual marker; CL: classifier; DE: de-particle; NEG: negation; PL: plural marker; PRT: particle; RES: result. 
In view of the incompatibility of ma-questions with an indirect reading, we would be hard pressed to posit a whether-operator in a direct ma-question. Importantly, both ma-questions and A-not-A questions lend themselves to a rhetorical reading. This empirical pattern, hence, casts doubt upon deriving the rhetorical reading from whether.

Another issue is that the mapping between a wh-word and a negative quantifier presupposes that all shenme-RQs have a corresponding ordinary question construction that shares the same syntactic form. As we will introduce in Section 6, this surface parallelism cannot be maintained in all cases. Finally, this approach has yet to explain why shenme does not mean negation outside rhetorical questions.

2.2 Shenme-RQs are questions with no answers: An empty answer set approach

Another proposal, discussed by Xu (1999) and Yin (2009), among others, is that shenme-RQs should be analyzed as semantically the same as ordinary questions whose answer sets are nevertheless empty (for a similar view on English rhetorical questions, see Ladusaw 1980; Koshik 2003). The subsequent failure to answer the questions as ordinary ones triggers a polarity reversal. Cheung (2009) proposes a similar and well fleshed-out account, in which the interpretation of rhetorical questions is schematized as follows: ${ }^{3}$

(4) Rhetorical interpretation of a question of the form $\mathrm{p}$ (shenme)

a. Answer set: \{\}

b. There is no proposition $\mathrm{q}$ such that $\mathrm{q}$ is a true answer to $\mathrm{p}$ (shenme)

While we agree with this approach that the negative assertive content of shenmeRQs does not stem from a negative part of the construction, we believe that the approach still suffers from several problems. First of all, some shenme-RQs do not denote or imply any set of answers to $\mathrm{p}$ (shenme). Instead, they convey the reasons or motivations for negation. For example, the speaker in the above-mentioned example (1) (repeated below) does not ask the hearer what school (primary school, middle school, high school, or university) the latter would go to but intends that the hearer should not go to school. In other words, the usual answerhood condition in ordinary questions requiring a set of alternatives corresponding to the whatpart does not apply here.

(5) $\mathrm{Ni}$ nianji hai zheme xiao, shang shenme xue? you age still so young go what school 'You are still so young, what school do you go to?'

3 Cheung's object of study is a construction type that bears strong resemblance to rhetorical questions, which he terms negative wh-constructions. Nevertheless, Cheung specifically argues that the proposal he puts forward can be carried over to account for rhetorical questions. 
Likewise, in example (6) below, the speaker does not ask the hearer what kind of bath (hot water bath, cold water bath, or massage) the latter would take but advises the hearer not to take a bath.

(6) (In China, most people take a bath much earlier before going to bed rather than late into night.)

Yijing zheme wan le, ni xi shenme zao? already so late ASP you wash what bath

'It is already so late, what bath are you going to take?' (Intended: You should not take a bath.)

More importantly, however, the above view requires that rhetorical questions be treated semantically the same as ordinary questions. While some shenme-RQs share the same string as ordinary questions and can lead to ambiguous interpretations, which will be disambiguated by whether shenme is stressed or not (Li 1990; Shao 1996; Shou 2002), there are other shenme-RQs that are syntactically idiosyncratic and distinct from ordinary questions. For this class of shenme-RQs, it is unclear how to interpret them in the same way as ordinary questions. For example, Yang (2014) finds that the rhetorical questions with shenme occurring initially do not have corresponding ordinary question forms. We will explore in more detail the syntactically idiosyncratic shenme-RQs in Section 6.

\subsection{Negation is attributed to the whole shenme-RQ construction rather than to shenme: A constructional approach}

Inspired by Goldbergian construction grammar (Goldberg 1995, Goldberg 2006), Wang (2003), Wu (2011), and Zhu (2013) claim that it is the shenme-RQ construction, rather than the interrogative word shenme, that carries the negative meaning. In this paper, we agree with the constructional view that the interrogative word, shenme, by itself does not carry any negative meaning, nor is it an epistemic or deontic negative modal (e.g., Jiang and Shi 2008; Wang 2017). It only performs the function of forming a rhetorical question and, at the most, it can be a rhetorical question marker. Consequently, we hold that epistemic and deontic negations are attributed to the whole shenme-RQ construction. However, previous constructional works leave much to be desired. For example, they do not provide a programmatic, implementable account of how this constructional meaning arises. In what follows, we seek to address this problem with a rhetorical syllogism-based theory as the analytical framework to explain how the negative meaning of shenme-RQs is deduced. ${ }^{4}$

4 Before proceeding, it is worth pointing out that the rhetorical question reading is no longer available if there is another scopal element within the question sentence. For instance, the following examples show that some elements (a negator mei 'not yet', a modal yuanyi 'want', and a quantificational adverb changchang 'often') resist a rhetorical question reading and, instead, force an ordinary question reading:

(i) a. $\mathrm{Ni}$ mei kan shenme dianying? $\left(\sqrt{ } \mathrm{Q},{ }^{*} \mathrm{RQ}\right)$

you not see what film 


\section{Theoretical framework: Enthymeme}

A dialectic syllogism consists of three propositions: the major premise, which is usually a general statement of something; the minor premise, which is often a specific description of something; and the conclusion drawn from the premises. A classical example of syllogism is demonstrated as follows:

(7) Major premise: All men are mortal.

Minor premise: Socrates is a man.

Conclusion: Socrates is mortal.

In his Rhetoric, Aristotle names the use of syllogism in rhetoric or daily communication "enthymeme" or "rhetorical syllogism". Compared with dialectic syllogism, enthymeme possesses two distinct features: incompleteness and probability (Walton 2001, Walton 2008; Yuan and Jiang 2010). In a dialectic syllogism, all the propositions, including the conclusion drawn, are explicitly stated, but in daily communication, there is no need to mention any of the propositions if it is a familiar or assumed fact, since the hearer can fill them in during reasoning. As a result, an enthymeme is an elliptical, reduced, and incomplete syllogism. A case in point is example (8):

(8) Mary will fail her exam because she has not reviewed the course materials.

In example (8), the missing major premise that can be retrieved from one's commonsensical knowledge is as follows: those who have not reviewed the course materials will fail in their examinations. In understanding an enthymeme, the hearer has to do the reasoning by filling in the implicit proposition. The meaning of the assumed proposition is determined and unambiguous (Paglieri and Woods 2011), but it can take different syntactic forms. Different hearers may fill in different sentences for the same implicit proposition, but the main meaning of those different sentences should be the same.

Unlike the propositions in a dialectic syllogism, which are always necessary and true, the premises of an enthymeme are usually true and probable, although some of them may be necessary. Therefore, the conclusion of an enthymeme is usually true or plausible. That is to say, the conclusion of an enthymeme allows for exceptions and can be refuted. For instance, imagine a scenario in which Mary

\footnotetext{
b. Ni yuanyi kan shenme dianying? ( $\mathrm{V} Q, * \mathrm{RQ})$

you want see what film

c. Ni changchang kan shenme dianying? $(\sqrt{ } \mathrm{Q}, * \mathrm{RQ})$

you often see what film

It might then be the case that the negative inference of a shenme-rhetorical question and the speech force it carries are subject to further scopal constraints. This is a broad topic that warrants more detailed investigations in the future. At present, we still do not know how to capture this empirical pattern in our account. See Pan (2014) and Yang (2014) for more discussions of the empirical phenomenon. We thank an anonymous reviewer for raising this issue for us.
} 
works hard during the school term and is quite familiar with the course materials, she might do quite well in the examination. In such a case, example (8) is false.

Enthymemes are widely used in natural language discourse. For example, an enthymeme can be used to reveal how an implicature is generated (Yuan and Jiang 2010). In example (9) below, Mary only utters the major premise: She would not drive any expensive car. Peter has to add the missing minor premise: Mercedes is an expensive car, which can stem from his encyclopedic knowledge, and works out the implicature as a conclusion: Mary would not drive a Mercedes. Likewise, enthymeme can also be applied to the derivation of the meaning of rhetorical questions (Ilie 1999), including the deduction of the negative meaning of shenmeRQs, which will be explored in Section 4.

(9) Peter: Would you drive a Mercedes?

Mary: I would not drive any expensive car.

(Sperber and Wilson 1995: 194)

\section{The deduction of the negative meaning of shenme-RQs}

Constructions originate from the context or the discourse in that they are the abstractions of the recurrent commonalities of their usage events (Langacker 2001, Langacker 2008). To specify or understand the meaning of a construction, one needs to refer to the contextual information and one's encyclopedic knowledge. Rhetorical questions are no exception since the answer to a rhetorical question lies not in the question itself but in the context (Li 1990). Likewise, the meaning of shenme-RQs also lies in the context in which they are embedded or situated. The negative conclusion implicit in the context is the answer to a shenme-RQ.

We follow the view articulated by Langacker $(1990,2008)$ that the meaning of a construction does not correspond to its truth-conditional values, nor does it derive automatically from the context. Instead, the speaker or hearer has to construct or deduce it by drawing on contextual information and her or his encyclopedic knowledge on the one hand, and cognitive abilities such as comprehending metaphor and conceptual blending on the other hand. When the speaker uses a shenme$\mathrm{RQ}$, she or he has to provide the necessary background information, including premises, so that the hearer can work out the intended negative interpretation of the shenme-RQ; otherwise, the message of the speaker's shenme-RQ will not be successfully deduced by the hearer. If the speaker assumes that the relevant premise is implicit in the context or the encyclopedic knowledge shared by both the speaker and the hearer, ${ }^{5}$ she or he will not state the premise explicitly and let the hearer to fill it in and work out the intended message of the shenme-RQ. On

5 Sometimes the shared context and encyclopedic knowledge may be not known to the outsider of the conversation in which the shenme-RQ is embedded. As a result, the premises are not available to the outsider. That is why shenme-RQs are usually preceded or followed by relevant premises in written language but are, at times, unavailable in spoken Chinese or hard to retrieve. 
the other hand, the hearer presumes that the speaker is cooperative and her or his utterance is relevant to the speech event (Grice 1975; Sperber and Wilson 1995). Thus, triggered by a shenme-RQ - or by a word or a phrase in a shenme-RQ - the hearer is expected by the speaker to fill in the implicit premise from the context or from her or his encyclopedic knowledge, and together with the explicit premise, deduce the negative conclusion, namely, the meaning of the shenme-RQ. A word or an expression not only profiles what it designates but also provides an access to an array of encyclopedic knowledge related to the word or expression in question (Langacker 1990, Langacker 2008). In the shenme-RQ in example (10) below, $j i$ 'hurry' not only refers to the anxious desire of taking quick actions but also evokes the reason or purpose of taking quick actions, especially, the encyclopedic knowledge that one needs to hurry when she or he is pressed for time, which serves as the major premise for reaching the negative conclusion. Upon encountering the shenme-RQ in example (10), $j i$ directs the hearer to add the implicit major premise from her or his encyclopedic knowledge on the one hand and to seek the explicitly stated minor premise, and then deduce the implicit conclusion, namely, "we do not need to hurry", which is the answer to the shenme-RQ in example (10). This shows that although negation is the meaning of the whole shenme-RQ construction, it comes from the context where it is situated and is derived via enthymeme. That is to say, the context, be it linguistic or nonlinguistic, provides the necessary input or clue for seeking the negative answer to shenme-RQs, but the hearer has to reason out the negative interpretation.

(10) Ji shenme? Women you bu gan shijian. hurry what we even NEG press time

'What hurry? We are not even pressed for time.' (https://www.jianshu.com/p/b81ca15be258)

On the basis of the explanation above, the deduction of the negative meaning of the shenme-RQ in example (10) can be demonstrated in the following:

(11) The implicit major premise: One needs to hurry when pressed for time.

The explicit minor premise: We are not pressed for time.

The deduced conclusion: We do not need to hurry.

It can be seen from deduction structure (11) that the negative interpretation of shenme-RQs can not be attributed to the use of shenme, which just performs the function of forming a rhetoric question, as said before, or any other words. Instead, the negative interpretation operates only at the semantic-pragmatic level involving neither syntax nor lexicon (Kay 1997: 184). That is, the shenme-RQ only links its pragmatic force of negation with its semantic representation. What is peculiar is that it retains its negative interpretation even if it is embedded under a bridging verb as a complement, such as in example (12):

(12) Meiyou mai fangzi, wo bu zhidao ni jie shenme hun. not buy house I not know you get what marriage 'I do not know how you can get married without buying a house.' 
The deduction structure in (11) above also shows that enthymematic reasoning can be straightforward, simple, and clear. Moreover, compared with the other approaches for addressing the negative meaning of shenme-RQs, as reviewed in Section 2, the enthymematic approach has several other merits. Firstly, according to Han (2002), if shenme is mapped into a negative quantifier, which takes scope over the whole propositional content of a shenme-RQ, the shenme-RQ always expresses the negative meaning and allows no exceptions. Therefore, the negative-shenme approach cannot handle cases where there are indeed answers or exceptions to the shenme-RQs, which our enthymematic approach can readily accommodate. As the enthymeme is based on the probability that the premises are plausible and may admit exceptions, the conclusion deduced from the premises of an enthymeme may be refuted. Consequently, an enthymeme can be readily used to explain the rebuttal of the negative meaning of shenme-RQs. A case in point is seen in example (13).

"Dui ma, wenhua da geming jiushi gaizao ren de da
right PRT cultural great revolution just reform people DE great
geming. $\mathrm{Na}$ ji nian, wo bu jiu gaizao cheng jiatingfunan
revolution those few years I NEG just reform into houseman
le ma? Bu xin, ni-men wen Wenting, wo shenme bu
ASP PRT NEG believe you-PL ask Wenting I what NEG
gan? Shenme bu hui?"
do What NEG can
Lu Wenting mianqiang xiao dao: "Shenme dou hui, jiushi bu
Lu Wenting force
hui na xiedi."
can sew sole

"“Right, the Great Cultural Revolution is just a revolution of reforming people. During those years, was I not reformed into a houseman? Don't believe it? You can ask Wenting. What have I not done? What could I not do?" Lu Wenting forced a smile: "You could do any housework, but you could not sew the soles of shoes.",

(Abridged from Chen Rong, People at the middle age)

As a "houseman" (stay-at-home dad), one is expected to be able to do any housework, which is the major premise for the shenme-RQ in example (13). Triggered by the rhetorical question "What have I not done? What could I not do?" in example (13), the hearer is expected to retrieve the major premise from encyclopedic knowledge, seek the stated minor premise, and deduce the negative answer as demonstrated in deduction structure (14):

(14) The unstated major premise: A "houseman" can do any housework.

The stated minor premise: I was reformed into a "houseman".

The unstated conclusion: I could do any housework.

Just as the implicit major premise in syllogistic structure (14) is probable and allows for exceptions, the conclusion is refuted by the following rebuttal in example (13), i.e., "You could not sew the soles of shoes." 
Secondly, not every shenme-RQ involves a set of answers. There are no answers to some shenme-RQs, but they just express reasons for not doing something or motivations for negation, as we have mentioned in Section 2. For example, one cannot answer san shenme bu? 'What walk to take?' with san zao bu 'to take an early walk', san wan bu 'to take a late walk', san kuai bu 'to take a fast walk', and san man $b u$ 'to take a slow walk', or whatever, which are all unacceptable in Chinese. In fact, utterance (15) only expresses the reason for not taking a walk. ${ }^{6}$ In sum, the empty answer set approach cannot give a unified account for all shenme-RQs.

(15) Tian zheme wan le, qu san shenme bu? it so late ASP go take what walk

'It is so late, what walk are you going to take?'

Thirdly, one of the hallmarks of shenme-RQs is that the speaker and the hearer know the answer, as claimed in Caponigro and Sprouse (2007). The question is how the hearer knows that the answer is a given, so that there is no need to supply one; or how the speaker ensures that the hearer knows the answer and does not expect one. Our analysis shows that the answer is already given in the context and the hearer can work it out via enthymeme. The speaker expects the hearer to deduce the answer although the speaker may sometimes give the answer explicitly.

Finally, Grice's (1975) Cooperative Principle, especially the Relation Maxim, offers a general framework that can trigger the hearer to work out the negative meaning of shenme-RQs, but the framework does not elaborate on how the hearer deduces the negative polarity interpretation of shenme-RQs. The enthymematic approach proposed in this paper offers a mechanism for the deduction of the negative meaning of shenme-RQs.

In reasoning out the negative meaning of shenme-RQs, the hearer also needs to follow the rules of dialectic syllogism. Because the meaning of the shenme-RQ is negative unless it is modified by a negative word or particle such as mei 'not' or $b u$ 'not', the relevant rules that the hearer needs to abide by are as follows (Kelley 1990: 202):

(16) a. "No valid syllogism can have two negative premises."

b. "If either premise of a valid syllogism is negative, the conclusion must be negative; and if the conclusion is negative, one premise must be negative."

The above two rules ensure that only one of the premises is negative in order for the hearer to arrive at the negative meaning of shenme-RQs. It follows that two types of enthymeme or dialectic syllogism will be used to derive the negative meaning of shenme-RQs: One is the modus tollens type, in which the minor premise is negative, as illustrated in deduction structure (11) above; the other is the modus ponendo tollens type, in which the major premise is negative, as shown in deduction structure (24) below.

6 In China, rarely do people take a walk during late hours at night. 
The rules stated in (16) also entail that the premises must be positive in order for the hearer to arrive at a positive conclusion. Therefore, when a shenme-RQ is modified by a negative word or particle, the negative meaning of the shenme-RQ and the negative word cancel each other out, and the shenme-RQ will be given a positive interpretation. In this case, the modus ponens type of enthymeme applies. For instance, the negative word $b u$ 'not' is inserted into the shenme-RQ in example (17). Therefore, the shenme-RQ in example (17) is interpreted as a positive assertion. The major and minor premises should be positive to arrive at a positive interpretation.

(17) Neng zheng qian you shenme bu hao? Fazhan le able make money have what NEG good develop ASP shengchan, gaohuo le jingji, yu guo yu production invigorate ASP economy to country to min dou you li. people both have benefit

'What is not good with being able to make money? It develops production, invigorates the economy, and benefits both the country and the people.'

(Abridged from Huang Beijia, I want to be a good child)

The enthymematic structure to deduce the positive meaning of the shenme-RQ in example (17) can be demonstrated below:

(18) The implicit major premise:

All is good that develops production, invigorates the economy, and benefits both the country and the people.

The explicit minor premise:

Being able to make money develops production, invigorates the economy, and benefits the country and people.

The implicit conclusion: Being able to make money is good.

From the above exploration, it follows that the negative meaning of shenme-RQs is not contributed by the wh-word shenme but is worked out via enthymeme. That is to say, the hearer finds the explicitly stated proposition, fills in the unstated ones, and deduces the conclusion, which is the meaning of the shenme-RQs.

Caponigro and Sprouse (2007) hold that not only can rhetorical questions be answered, but they can also elicit a positive answer. But their conclusion is based on English who-based rhetorical questions. As our analysis shows, Chinese shenme-RQs can only receive the negative polarity interpretation. Thus, our working definition for shenme-RQs is that the speaker knows (and may give) the answer, but the hearer has to work out the negative answer with the help of the contextual information and her or his encyclopedic knowledge, as is clearly demonstrated above.

\section{The patterns of reasoning out the negative meanings of shenme-RQs}

To further apply enthymeme to the study of shenme-RQs, we first explore the patterns for deduction of their negative meaning. On the basis of those patterns, we 
then propose the procedure of how the hearer works out the negative meaning of shenme-RQs. In accordance with whether the major premise, the minor premise, and/or the conclusion are/is left out or unstated in an enthymematic structure, the logically possible patterns of reasoning out the negative meaning of shenme-RQs are demonstrated in Table $1 .^{7}$

\section{Table 1}

\begin{tabular}{|l|c|c|c|c|}
\hline Pattern & Major premise & Minor premise & Conclusion & Possibility \\
\hline 1 & + & + & + & $\times$ \\
\hline 2 & + & + & - & $\sqrt{ }$ \\
\hline 3 & + & - & + & $\times$ \\
\hline 4 & + & - & - & $\sqrt{ }$ \\
\hline 5 & - & + & + & $\times$ \\
\hline 6 & - & + & - & $\sqrt{ }$ \\
\hline 7 & - & - & + & $\times$ \\
\hline 8 & - & - & - & $\sqrt{ }$ \\
\hline
\end{tabular}

Notes: "+"means "stated"; “_” implies "unstated"; "×” means "impossible"; and " $\sqrt{ }$ " represents "possible".

What is unique to the shenme-RQ is that it does not require an answer unless it is refuted as in example (13) above. ${ }^{8}$ Therefore, Patterns $1,3,5$, and 7 are not possible, and they are ruled out because they all allow the conclusion to be stated explicitly. Moreover, Pattern 1 is not possible for another reason: it is not economical and unnecessary to state all the propositions in daily communication, especially the propositions that are obvious to both the speaker and the hearer. In theory, Pattern 8 is not possible either because there is no way to deduce the conclusion if both of the premises are left out. But the conclusion is deductible as will be shown in example (27) below if both premises are implied in the context or if parts of the premises are expressed explicitly.

7 In the current approach, whether the premises are stated or unstated depends, to a large extent, on the content of the immediately surrounding discourse. However, as yet, we do not have a working definition of the discourse structure other than an intuitive sense of which premise is included within the adjacent discourse and how to retrieve it. The references we have found and listed also include no formal definitions. We hope to leave this desideratum to future endeavors.

8 The speaker may give the answer explicitly. In this case, it may be necessary for the hearer to carry out enthymematical reasoning to verify and accept the answer given by the speaker, as in (i).

(i) Dianhua jiu yongbuzhao, ta mei you qinqi pengyou, yao dianhua telephone just not necessary, he not have relative friend, need telephone

zuo shenme?

do what

'No need for a telephone. He's got no relatives or friends, what is he doing with a telephone?' 
In fact, the remaining four logically possible patterns in Table 1 are attested by the authentic examples we have collected. They are renumbered and illustrated in the following subsections.

\subsection{Pattern 1: Deducing the conclusion}

The speaker will explicitly state both the major and minor premises if they are not known to the hearer. Therefore, the hearer has to extract the explicit premises and deduce the unstated conclusion, namely, the negative answer to the meaning of the shenme-RQ sentence, as in example (19).

(19) Du shifu dui erzi shuo: "Ni jiu zuo qiangong de huo ba. $\mathrm{Du}$ master to son say you just do mechanic DE job PRT "You shenme fazi ni?" erzi xiang. Ta zhidao die de piqi. have what way PRT son thought he know father DE temper Ruguo die yijing jueding le, yao xiang gaibian jianzhi shi if father already decide ASP need want change literally is

bu keneng de.

NEG possible DE

"Master Du said to his son: "You do the job of a mechanic."

"What way do I have?" thought the son. He knew his father's temper. If his father had already decided something, it was literally impossible to change his mind.'

(Abridged from $\mathrm{Hu}$ Wanchun, The family's problem)

The shenme-RQ in example (19) can trigger the reader in this case to seek the major and minor premises that are explicitly stated preceding or following "What way do I have?" to arrive at the negative answer, as shown in deduction structure (20).

(20) The explicit major premise:

It was literally impossible to change my father's decision once he had made it. The explicit minor premise:

My father had decided to make me do the job of a mechanic.

The implicit conclusion:

It was impossible for me to change my father's decision for me to do the job of a mechanic.

\subsection{Pattern 2: Filling in the minor premise and deducing the conclusion}

Since both the speaker and the hearer are present in the situational context, there is no need for the speaker to explicitly mention the minor premise because it is clear to the hearer. As a result, the speaker just mentions the major premise and lets the hearer fill in the minor premise and deduce the conclusion. In example (21) below, only the major premise is given:

Yupanger dajiaodao: "Zhe zuowen timu tai nan xie le."
Yupanger scream this composition title too hard write ASP


Jin Ling xue zhe laoshi de kouwen shuo: "Nan shenme? Jin Ling learn ASP teacher DE tone say difficult what Ken dong naojin jiu bu nan." willing use brains just NEG hard

'Yupanger screamed: "It is too hard to write a composition on this title." Jin Ling imitated the teacher's tone, saying: "What is difficult? If one is willing to think hard, nothing will be difficult.", (Abridged from Huang Beijia, I want to be a good child)

It is almost a truism that nothing will be hard if one is willing to think hard, which can induce the hearer to fill in the minor premise from the context in example (21) and deduce the negative answer. The deduction of the negative meaning of the shenme-RQ in example (21) is spelled out as follows in deduction structure (22):

(22) The stated major premise: If one is willing to think hard, nothing will be difficult.

The unstated minor premise: Be willing to think hard to write this composition. The unstated conclusion: The composition will not be difficult for you.

\subsection{Pattern 3: Filling in the major premise and deducing the conclusion}

If the major premise is a general statement implicit in the encyclopedic knowledge of both the speaker and the hearer, the hearer has to fill in the major premise, identify the stated minor premise, and work out the conclusion, namely, the answer to the shenme-RQ. A case in point is example (23), in which the omitted major premise is that people do not usually play chess at a chaotic place in China.

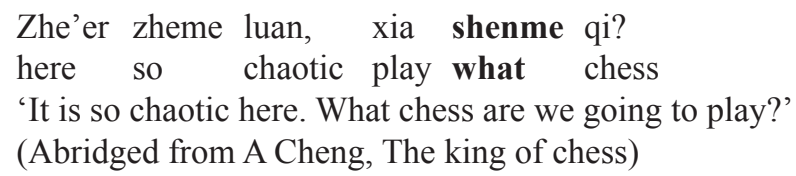

Prior to uttering the shenme-RQ in example (23), the speaker explicitly states the minor premise: It is so chaotic here. Triggered by the shenme-RQ, the hearer extracts the major premise as explained above from her or his background knowledge and arrives at the negative answer, together with the stated minor premise, as demonstrated in deduction structure (24):

(24) The unstated major premise: People do not usually play chess at a chaotic place. The explicit minor premise: It is so chaotic here.

The unstated conclusion: We should not play chess here.

Sometimes, the major premise is implicit in the linguistic context. The hearer has to work it out and deduce the negative meaning of the shenme-RQ sentence, together with the explicit minor premise. For instance, the unstated major premise of the shenme-RQ in example (25) is the implicature of the sentence in bold, which the hearer has to infer: one needs to have the certificates to buy building materials. 
(25) Xunwen youguan shangdian, cai zhidao mai yi kuai zhuan inquire relevant store only know buy one CL brick dei you bendi san ji zhengming. Jiezhe ziran shi should have local three level certificate then naturally is zhao shengchan dui, dadui ganbu da zhengming. Renjia find production team brigade officials make certificate they xiaoxiao shuo: "Da zhengming you shenme yong? Gei le laugh say make certificate have what use give ASP zhengming, ni ye mai bu dao." certificate you also buy NEG RES

'Having inquired at the relevant stores, he only found that to buy a brick, he should have the certificates of local three levels. Then naturally he applied to the officials of the production team and the production brigade for certificates. They laughed and said: "What is the use of making you the certificates? You cannot buy any building materials even if we make them for you."' (Abridged from Gao Xiaoshen, Li Shunda built a house)

The deduction of the negative meaning of the shenme-RQ sentence in example (25) can be shown in deduction structure (26):

(26) The implicit major premise:

One needs to have the certificates to buy building materials.

The explicit minor premise:

You cannot buy any building materials even if we make you the certificates.

The implicit conclusion:

It is of no use to make you the certificates.

\subsection{Pattern 4: Filling in the major and minor premises}

When both the major and minor premises are generalizations known to both the speaker and the hearer, the hearer can fill them in and work out the negative meaning of the shenme-RQ. It is known in China that people who are close to each other, such as intimate friends or a father and his daughter or son, do not need to be overly polite to each other. It is also known that a married couple are usually close to each other. In example (27), both the major and minor premises are unstated and the hearer has to add them to work out the negative meaning of the shenme-RQ. ${ }^{9}$

9 In example (27), liangkouzi 'a married couple' has the generic reading, referring to married couples in general. This is clear in the following example:

Jin Ling is a plump primary school pupil whose mother wanted her to lose weight, but Jin Ling's grandmother liked to cook her delicious dishes. Her mother objected and her grandmother replied as follows:

(i) Xiaohaizi jian shenme fei?

little children lose what weight

'What weight do little children lose?'

(Abridged from Huang Beijia, I want to be a good child) 
(27) Dang He Luli he zhangfu Rong Guohuang dou shi daifu de when He Luli and husband Rong Guohuang both were doctors DE shihou, bici zhijian da dianhua, tuo ban ge shenme shi, mo time each.other among make phone ask do CL what thing end liao dou yao xiang duifang daosheng xiexie. Pangbian tingdao ASP even need to other side say thank nearby hear de ren qiguaide wen: "Liangkouzi keqi shenme?" DE people curiously ask couple polite what

'When He Luli and her husband Rong Guohuang were both doctors, they telephoned the other to ask for help with something and would thank one another in the end. People who were nearby and overheard their phone call curiously asked: "What do a married couple need to be polite to each other for?",

(Abridged from He Luli's yesterday and today, http://www.xzbu.com/5/view-1205262.htm)

The enthymematic deduction of the negative meaning of the shenme-RQ in example (27) is shown in reasoning structure (28):

(28) The unstated major premise:

People who are close to each other do not need to be polite to each other.

The unstated minor premise:

A married couple are usually close to each other.

The unstated conclusion:

A married couple do not need to be polite to each other.

On the other hand, the negative meaning of the shenme-RQ in example (27), i.e., the unstated conclusion in reasoning structure (28), can function as the major premise to derive the implicature of the shenme-RQ in example (27), together with the implicit minor premise, as spelled out in syllogistic structure (29):

(29) The unstated major premise:

A married couple do not need to be polite to each other.

The unstated minor premise:

He Luli and Rong Guohuang were a married couple.

The unstated conclusion:

He Luli and Rong Guohuang did not need to be polite to each other.

The above four patterns of logically possible and empirically attested patterns of reasoning out the negative meaning of shenme-RQs are summarized in Table 2.

Throughout the whole discourse, the grandmother used Jin Ling's name to address her, but only used xiaohaizi 'little children' in the above utterance. So, it refers to little children in general rather than any specific ones. 
Table 2

\begin{tabular}{|l|c|c|c|}
\hline Pattern & Major premise & Minor premise & Conclusion \\
\hline 1 & + & + & - \\
\hline 2 & + & - & - \\
\hline 3 & - & + & - \\
\hline 4 & - & - & - \\
\hline
\end{tabular}

From Table 2, the procedure for deducing the negative meaning of shenme-RQs is proposed in scheme (30):

(30) i. Find in the discourse whether there is any general statement that is related to the shenme-RQ and can act as the major premise.

ii. If there is such a major premise, i.e., the major premise is explicitly stated, find whether there is any specific statement that is related to the shenmeRQ and can act as the minor premise. If there is such a minor premise, together with the stated major premise, deduce the conclusion (Pattern 1); otherwise, fill in the implicit minor premise and deduce the conclusion together with the explicit major premise (Pattern 2).

iii. If there is no such major premise in the discourse, fill in the major premise and find whether there is any specific statement that is related to the shenme-RQ and can be the minor premise. If there is indeed such a minor premise, together with the added major premise, deduce the conclusion (Pattern 3). If there is no such minor premise, fill in the minor premise and deduce the conclusion together with the added major premise (Pattern 4).

The whole procedure is presented in Figure 1.

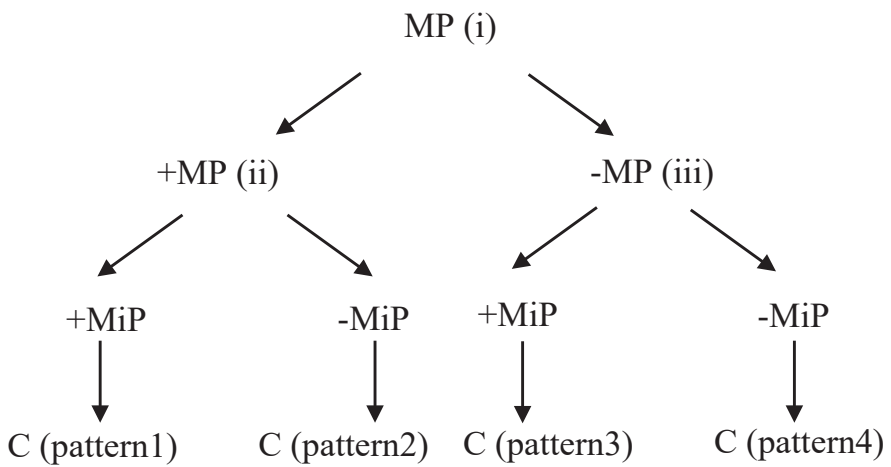

Figure 1 The procedure for deducing the negative meaning of shenme-RQs

Notes: MP: major premise; MiP: minor premise; C: conclusion. 


\section{The entrenchment and conventionalization of the negative meaning of shenme-RQs}

Having examined the deduction of the negative meaning of shenme-RQs via enthymeme, we have to recognize the entrenchment and conventionalization of shenme-RQs. In line with the usage-based approach to language (Langacker 2008, Langacker 2016), a linguistic structure will be entrenched in the mind of its users via repeated use so that it becomes a cognitive routine. The hearer will just associate the structure with a certain semantic or pragmatic force without working out the meaning every time she or he hears the structure in question. When the hearer applies the modus tollens syllogism to the deduction of meaning of a whyconditional construction, such as example (31), the first time she or he encounters it, (s)he will make a full calculation of the pragmatic force of its meaning (Kay 1997).

(31) If you are smart, why aren't you rich?

(Kay 1997)

Contrarily, when the why-conditional construction takes on conventionality, the hearer will just pair it with the pragmatic force without any calculation. The same point is made by Michaelis and Feng (2015) in their study of the sarcastic Split Interrogative construction, such as in example (32).

(32) Where were you when I needed you? Off chasing butterflies?

(Michaelis and Feng 2015)

Likewise, we suggest that the negative meaning of shenme-RQs is subject to conventionalizable entrenchment as a function of increased use. Thus, the hearer readily attaches the negative interpretation to a shenme-RQ without conducting the enthymematic reasoning every time she or he encounters it even when the relevant context for retrieving the missing premises is not provided. Specifically, we want to point out several syntactic distributional environments, noted in the literature (Li 1990, Shao 1996, and Yang 2014, among others), which facilitate the hearer to identify entrenched shenme-RQs.

Firstly, shenme is "fully stressed" (Chao 2004 [1968]: 666), i.e., stressed to a higher degree than the normal stress (Shao 2013), when it appears initially as the modifier of a word, a phrase, or a clause in a (possibly elliptical) rhetorical question, or when it is moved before the verb. For example, shenme is fully stressed as a modifier in example (33a), and the shenme-RQ conveys the pragmatic force that he is not a qualified doctor or even not a doctor at all. In such a case, shenme can be followed by a cursing word like goupi 'dog's fart' to encode the speaker's attitude compatible with the negative meaning. ${ }^{10}$ Also, in example (33b), shenme

10 Yang (2014) finds that cursing words (taboo words in his wording) can reinforce negation when shenme occurs postverbally in a rhetorical question, but he does not mention whether cursing 
is fully stressed as it is fronted before the verb dong 'understand'. ${ }^{11}$ In isolation, the shenme-RQ in example (33b) can mean the opposite even though the related context for retrieving the premises is not offered: He understands everything. As shenme is a variable in example (33b), it ranges over "all those materials" and the whole question receives the positive interpretation, together with the negative word $b u$ 'not': He understands all those materials.

(33) a. Shenme (goupi) boshi? Lian zhonguozhiwang dou bu zhidao. what (dog.fart) doctor even CNKI all not know

'What (the hell) doctor? He even does not know CNKI.'

(CNKI [China National Knowledge Infrastructure] is a reference database that Chinese graduate students and doctoral candidates are supposed to know.)

b. Wo shenme bu dong? Zhexie cailiao wo dou kan

I what not understand those materials I all read guo le.

ASP le

'What do I not understand? I have read all those materials.'

In contrast, shenme is unstressed in other positions as the object, the modifier of the object, or the adjunct in a rhetorical question (Shao 2013; Yuan and Liu 2016; Yang and Tsai 2019). In ordinary questions, shenme is stressed, as it is the focus of an information request. However, shenme is no longer the focus of information seeking in a rhetorical question, and thus it is unstressed as in example (34) where the stress falls on the verb. If the stress falls on shenme in example (34), the shenmebased sentence will be an ordinary question. In other words, the stress that shenme receives disambiguates whether a shenme-based sentence is rhetorical or not.

(34) Chi shenme? Fan hai meiyou shao.

eat what dinner yet not cook

'What to eat? The dinner has not yet been cooked.'

(Intended: There is nothing to eat.)

words can strengthen the speaker's negative attitude when shenme occurs initially or preverbally in a rhetorical question. Here, we differ from Yuan and Liu (2016), who observe the use of cursing words during negation but hold that cursing words encode negation in shenme-RQs.

11 The role of stress is illustrated by the following minimally contrasted examples (bold face indicates stress):

(i) a. Ta shenme bu dong?

he what not understand

b. Ta shenme bu dong?

The stressed (a)-example receives a rhetorical reading. The (b)-example, on the other hand, receives a regular question reading. We thank an anonymous reviewer for suggesting to us the construction of a minimal pair. 
Secondly, the unstressed shenme can follow an intransitive verb or adjective as an object (Chao 2004 [1968]: 340) or an adjunct (Kurafuji 1996; Ochi 2004) to form rhetorical questions, which can be termed as the "Vi-shenme" rhetorical questions such as those in example (35): $:^{2}$

a. Ni pao shenme? Wo you shi yao gen ni shangliang. you run what I have matter want with you consult 'Why do you run away? I would like to consult you about something.'

b. Ni gaoxing shenme? Zheme yidian xiao shi. you glad what such a bit little thing 'What are you glad at? It is such a bit little thing.' (Intended: You should not be glad at such a little thing.)

What is unique is that only the wh-word shenme can follow an intransitive verb or adjective to form a rhetorical question, especially the one that literally asks for reasons (Pan 2014). For example, in comparison with example (35), both $\mathrm{Ni}$ gaoxing shui? 'You glad who?' and Ni gaoxing nali? 'You glad where?' are not acceptable in Mandarin Chinese.

Thirdly, the verb or adjective can be reduplicated after shenme to form rhetorical questions where the reduplicated form is unstressed as in example (36):
a. Kai ge wanxiao, ji
shenme ji?
play CL joke anxious what anxious
'Just play a joke. What are you anxious about?'
(Intended: You should not feel anxious.)

b. Ni xiao shenme xiao? Wo shuo de shi shishi. you laugh what laugh I say DE is fact

'Why do you laugh? What I have said is a fact.'

In addition, what is peculiar is that only the interrogative word shenme can be followed by the reduplicated verb or adjective to form a rhetorical question. If shenme is replaced by shui 'who' in examples (36a) and (36b), the resulting sentence is either unacceptable for example (36a) or acceptable yet qua an

12 Both Kurafuji (1996) and Ochi (2004) find that in a number of languages such as Japanese, Turkish, German, Greek, Russian, and Hungarian, intransitive verbs can take why-like "what" as an adjunct to form questions for expressing incongruence. Following Kurafuji and Ochi, Tsai (2011) and Yang (2014) argue that the "Vi+ shenme" rhetorical questions also literally ask for reasons. We would like to point out that Chinese "Vi + shenme" rhetorical questions can also literally ask for manners, as follows:

(i) $\mathrm{Ni}$ na zou pugaijuan, wo shui shenme?

you take away bedding I sleep what

'If you take away the bedding, how can I sleep?' (Intended: I cannot sleep if you take away the bedding.) 
ordinary interrogative question for example (36b). We call this type of shenme-RQ the "V-shenme-V" rhetorical questions. Another evidence for the peculiarity of shenme-RQs is that only shenme can occasionally be flanked on both sides by a noun, a pronoun, or even an exclamatory word to form rhetorical questions where the first element is coerced into a verb, as illustrated by Wu (2011) and Zhu (2014). Moreover, "V-shenme-V" rhetorical questions do not have the corresponding ordinary question forms.

Finally, shenme can be inserted inside a compound. In example (37a), it is inserted inside a verb-theme compound to form a rhetorical question. Moreover, shenme can also be inserted into adjectival and nominal compounds to form rhetorical questions, as a result of which the first element of the compounds is coerced into a verb and the second element, the object or theme, as in examples (37b) and (37c):

a. Xiao haizi, daren jianghua, cha shenme zui? little child adult speak insert what mouth 'Little child, how come you interrupt adults when they are speaking?'

b. Ni ji shenme dong? Kaoshi dou meiyou jige. you excite what move exam even not pass 'Why do you get excited? You did not even pass the exam.'

c. Zhuan shenme jia? Zhege jiandan de wenti dou specialize what specialist this simple DE problem even jiejue bu liao. solve not ASP

'What specialist? He cannot even solve a problem this simple.'

Syntactically, shenme modifies the objects as in example (37), but it "refers to" or modifies the whole compound (Chao 2004 [1968]: 339). Again, no interrogative word other than shenme can be interposed into verbal, adjectival, or nominal compounds to form a rhetorical question. This type of shenme-RQs can be called the "V-shenme-theme" rhetorical questions.

Of all the types of shenme-RQs, the Vi-shenme, the $\mathrm{V}$-shenme-V, and the V-shenme-theme types are partially filled constructions (Goldberg 1995, Goldberg 2006) or constructional idioms (Jackendoff 2002) in that their negative interpretations are fully entrenched and conventionalized or recognized in the Mandarin community via frequent use. Due to the form-meaning correspondence, the hearer is able to derive the negative meaning directly from the idiosyncratic forms of these constructional idioms. That is to say, speakers or hearers can readily and safely attach the negative meaning to those types of shenme-RQs without explicit inferential processes, unless they are indicated otherwise. 


\section{Conclusion}

Chinese shenme-RQs have a question form but do not elicit an answer because the answer lies in the context. The speaker knows that the hearer knows the answer because the hearer can work out the answer via enthymeme. That is to say, the hearer, triggered by the shenme-RQ, extracts the explicit premise, fills in the implicit premise from the context or from her or his encyclopedic knowledge, and deduces the answer. This explains how the negative inference of shenme-RQs arises.

Having said that, we must point out the entrenchment and conventionality of the negative meaning of the shenme-RQ. The first time one hears a shenme-RQ, she or he has to make the enthymematic reasoning to get the negative answer. Nevertheless, the negative meaning of the shenme-RQ will be entrenched in the mind of the hearer and conventionalized in the Mandarin community with increased use. Therefore, the hearer will readily attach the negative interpretation to the shenme-RQ without conducting the enthymematic reasoning every time she or he encounters a shenme-RQ, especially when the shenme-RQ is an instance of the Vi-shenme, the V-shenme- $\mathrm{V}$, and the $\mathrm{V}$-shenme-theme types.

Cognitive linguistics maintains that language is an integral part of human cognition. Any revealing account of language should mesh with well-established or psychologically plausible abilities (Langacker 2008). So far, cognitive linguistics has succeeded in applying categorization, metaphor, metonymy, conceptual blending, construal, and so on to the study of language. To develop further, cognitive linguistics needs to apply more cognitive abilities to the description and explanation of language. Maybe enthymematic reasoning is just one of the general cognitive abilities that deserves more attention and needs to be applied to the study of other linguistic structures.

\section{Acknowledgments}

We would like to thank Aijun Huang, Xiaolong Lu, Laura Michaelis, Masao Ochi, Changsong Wang, Yin Wang, Sherman Wilcox, Ying Yuan, Hua Zhong, and others for offering us valuable references and suggestions. Our heartfelt gratitude also goes to the anonymous reviewers for their illuminating comments and advice. Needless to say, the remaining errors in this paper are our own responsibility.

\section{Sources}

A, Cheng. 2003. The king of chess. In Zhu, Donglin (ed.), Selected readings of modern Chinese literature, vol. 3, 283-307. Beijing: Higher Education Press.

Chen, Rong. 2003. People at the middle age. In Zhu, Donglin (ed.), Selected readings of modern Chinese literature, vol. 3, 202-260. Beijing: Higher Education Press. 
Gao, Xiaoshen. 2009. Li Sunda built a house. In Zhu, Donglin (ed.), Selected readings of modern Chinese literature, vol. 3, 178-191. Beijing: Higher Education Press.

$\mathrm{Hu}$, Wanchun. 2003. Family's problem. In Zhu, Donglin (ed.), Selected readings of modern Chinese literature, vol. 3, 121-132. Beijing: Higher Education Press.

Huang, Beijia. 2006. I want to be a good child. Nanjing: Jiangsu Children's Press.

\section{References}

Caponigro, Ivano \& Jon Sprouse. 2007. Rhetorical questions as questions. In Estella Puig-Waldmüller (ed.), Proceedings of Sinn und Bedeutung 11, 121-133. Barcelona: Universitat Pompeu Fabra.

Chao, Yuen Ren. 2004[1968]. A grammar of spoken Chinese. Vol. 3 of The complete works of Yuen Ren Chao. Beijing: The Commercial Press.

Cheung, Yam-Leung. 2009. Negative wh-construction and its semantic properties. Journal of Eastern Asian Linguistics 18. 297-321.

Goldberg, Adele. 1995. Constructions: A constructional approach to argument structure. Chicago: Chicago University Press.

Goldberg, Adele. 2006. Constructions at work: The nature of generalization in language. Oxford: Oxford University Press.

Grice, Paul. 1975. Logic and conversation. In Peter Cole \& Jerry Morgan (eds.), Syntax and semantics 3: Speech acts, 41-58. New York: Academic Press.

Han, Chung-Hye. 2002. Interpreting interrogatives as rhetorical questions. Lingua 112. 201-229.

Ilie, Cornelia. 1999. Question-response argumentation in talk shows. Journal of Pragmatics 31. 975-999.

Ilie, Cornelia. 2009. Rhetorical questions. In Louise Cummings (ed.), The Routledge pragmatics encyclopedia, 435-438. London: Routledge.

Jackendoff, Ray. 2002. Foundations of language. Oxford: Oxford University Press.

Jiang, Wei \& Yuzhi Shi. 2008. Shenme de fouding gongyong [The function of the negative marker of shenme]. Linguistic Sciences 34. 270-277.

Kay, Paul. 1997. Constructional modus tollens and the level of conventionality. In Paul Kay (ed), Words and the grammar of context, 175-188. Stanford: CSLI Publications.

Kelley, David. 1990. The art of reasoning with symbolic logic. New York \& London: W.W Norton \& Company.

Koshik, Irene. 2003. Wh-questions used as challenges. Discourse Studies 5. 51-77.

Kurafuji, Takeo. 1996. Unambiguous checking. In Masatoshi Koizumi, Masayuki Oishi, \& Uli Sauerland (eds.), Proceedings of the Second Conference on Formal Approaches to Japanese Linguistics (MIT Working Papers in Linguistics 29), 81-96. Cambridge: MIT. 
Ladusaw, William. 1980. Polarity sensitivity as inherent scope relations. New York: Garland.

Langacker, Ronald. 1990. Concept, image, and symbol: The cognitive basis of grammar. Berlin \& New York: Mouton de Gruyter.

Langacker, Ronald. 2001. Discourse in cognitive grammar. Cognitive Linguistics 12: 143-188.

Langacker, Ronald. 2008. Cognitive grammar: A basic reader. New York: Oxford University Press.

Langacker, Ronald. 2016. Working toward a synthesis. Cognitive Linguistics 27(4). 465-477.

Lee-Goldman, Russell. 2006. Rhetorical questions and scales: Just what do you think constructions are for? Paper presented at the International Conference on Construction Grammar 4, Tokyo University, 1-3 September.

Li, Yuming. 1990. Fanwenju de goucheng jiqi lijie [The formation and understanding of rhetorical questions]. Yindu Journal 3. 91-99.

Lü, Shuxiang. 1985. Jindai hanyu zhidaici [Demonstratives and pronouns of modern Mandarin Chinese]. Shanghai: Xuelin Press.

Lü, Shuxiang. 2005[1980]. Xiangdai hanyu babai ci [Eight hundred words of contemporary Chinese]. Beijing: The Commercial Press.

Michaelis, Laura \& Hanbing Feng. 2015. What is this, Sarcastic Syntax? Constructions and Frames 7. 148-180.

Ochi, Masao. 2004. How come and other adjunct Wh-phrases: A cross-linguistic perspective. Language and Linguistics 5. 29-57.

Paglieri, Fabio \& John Woods. 2011. Enthymemes: From reconstruction to understanding. Argumentation 25. 127-139.

Pan, Victor Junnan. 2014. Deriving special questions in Mandarin Chinese: A comparative study. In Jong-Un Park \& 1l-Jae Lee (eds.), Comparative Syntax: Proceedings of the 16th Seoul International Conference on Generative Grammar, 349-368. Seoul: The Korean Generative Grammar Circle.

Progovac, Ljiljana. 1993. Negativity polarity: Entailment and binding. Linguistics and Philosophy 16. 149-180.

Rohde, Hannah. 2006. Rhetorical questions as redundant interrogatives. In Henry Beecher, Shin Fukuda \& Hannah Rohde (eds.), San Diego Linguistics Papers 2, 134-168. San Diego, CA: Department of Linguistics, University of California, San Diego.

Sadock, Jerrold. 1971. Queclaratives. In Papers from the Seventh Regional Meeting of the Chicago Linguistic Society, 223-232. Chicago: Chicago Linguistics Society.

Sadock, Jerrold. 1974. Towards a linguistic theory of speech acts. New York: Academic Press.

Shao, Jingmin. 1996. Xiandai hanyu yiwenju yanjiu [A study of modern Chinese rhetorical questions]. Shanghai: East China Normal University Press.

Shao, Jingmin. 2013. Yiwenju de jiegou leixing yu fanwenju de zhuanhua guanxi yanjiu [The conversion relationship between the structure types of interrogative 
sentences and rhetorical questions]. Hanyu Xuexi [Chinese language learning] 2. 3-10.

Shao, Jingmin \& Xiufeng Zhao. 1989. "Shenme" fei yiwen yongfa yanjiu [A study on the non-interroative usages of "what"]. Yuyan Jiaoxue yu Yanjiu [Language teaching and linguistic studies] 1. 26-40.

Shou, Yongming. 2002. Yiwen daici de fouding yongfa [The negative usage of the interrogative pronouns]. Journal of Shanghai Teachers University 31. 113-117.

Sperber, Dan \& Deirdre Wilson. 1995. Relevance: Communication and cognition, 2nd edn. Oxford: Blackwell.

Sprouse, Jon. 2007. Rhetorical questions and wh-word movement. Linguistic Inquiry 38. 572-580.

Tsai, Wei-tien Dylan. 2011. Cong "zhe hua cong he shuo qi” [Speaking from "where should I begin?"]. Yuyanxue Luncong [Essays on linguistics] 43. 194-208.

Walton, Douglas. 2001. Enthymeme, common knowledge, and plausible inference. Philosophy and Rhetoric 34. 93-112.

Walton, Douglas. 2008. The three bases for the enthymeme: A dialogical theory. Journal of Applied Logic 6. 361-379.

Wang, Haifeng. 2003. "A shenme B" jiegoushi chutan [On the construction "A shenme B"]. Journal of Sichuan University 126. 89-92.

Wang, Changsong. 2017. A study on noncanonical wh-particles from the prosodysyntax interface: A case study of shenme in "V shenme (V)/(NP)" construction. In Shengli Feng (ed.). Studies in prosodic grammar, vol. 2, 73-100. Beijing: Beijing Language and Culture University Press.

Wu, Danhua. 2011. "X shenme X" de jiegou xingzhi xintan [A new exploration of the structure "X shenme X"]. Journal of Central South University 17. 180-184.

$\mathrm{Xu}$, Shenghuan. 1999. Yiwenju tanxun gongneng de qianyi [The transfer of probing functions of interrogative constructions]. Zhongguo Yuwen [Studies of the Chinese language] 268. 3-11.

Yang, Barry Chung-Yu. 2014. Shenme gen shenme 'what and what'. Paper presented at the 10th Workshop on Formal Syntax \& Semantics (FOSS-10), National Quemoy University, Kinmen, November 22-23.

Yang, Yang \& Wei-Tian Dylan Tsai. 2019. Nianli yizhuan de yunlü yufa ji shiyan yanjiu [An experimental study of the prosodic syntax of force shift]. Shijie Hanyu Jiaoxue [Chinese teaching in the world] 1, 20-30.

Yin, Shuling. 2009. Xiandai hanyu fanwenju yanjiu [A study of modern Chinese rhetorical questions]. Ha'er'bin: Heilongjiang University Press.

Yuan, Ying \& Yan Jiang. 2010. Xiuci sanduanlun yu yuyi de yuyong tuidao [Rhetorical syllogism and implicature-drawing in pragmatic inference]. Foreign Language Teaching and Research 42. 97-103.

Yuan, Yulin \& Bin Liu. 2016. "Shenme"ju fouding yiyi de xingcheng yu shijie jizhi [On the formation and construal mechanism of the negative meaning of shenmesentences]. Shijie Hanyu Jiaoxue [Chinese teaching in the world] 3. 303-317.

Zhu, Jun. 2013. Fanwen goushi "you shenme X" de fouding moshi yu fouding dengji: Hudong jiaoji moshi zhong de yuyong fouding ge'an fenxi [The negation 
model and hierarchy of the rhetorical question "you shenme X": A case study of pragmatic negation in interactive modes]. Zhongguo Yuwen [Studies of the Chinese language] 357. 505-517.

Zhu, Jun. 2014. Fanwen goushi "X shenme X" de lichang biaoda gongneng kaocha [Expressive function of rhetorical question format " $\mathrm{X}+$ shenme $+\mathrm{X}$ " in negative position]. Hanyu Xuexi [Chinese language learning] 3. 20-27.

\author{
Chengru Dong \\ Mailing address: School of Foreign Languages, Soochow University, China \\ Email: dongchengru@126.com \\ Dawei Jin \\ Mailing address: School of Humanities, Shanghai Jiao Tong University, China \\ Email: daweijin@sjtu.edu.cn \\ Received: $\quad$ September 6, 2018 \\ Accepted: $\quad$ February 1, 2019
}




\title{
“什麼” 反問句否定意義推導的修辭三段論研究
}

\author{
董成如 ${ }^{1}$ 、金大衛 ${ }^{2}$ \\ 蘇州大學 ${ }^{1}$ 、上海交通大學 ${ }^{2}$
}

\section{摘要}

“什麼” 反問句研究的一個爭議問題是其否定意義如何產生的。本文試圖運用修辭 三段論探析其否定意義的推導。受 “什麼” 反問句或句中某個詞或短語的觸發, 聽話人提取明示的前提, 從語境或百科知識中補充出隱含的前提, 並推導出結論一一 “什麼” 反問句的意義。根據前提省略情況, 本文還探討了 “什麼” 反問句否定意 義的推導類型, 提出了推導的程序。雖如此, 經過反復使用後, “什麼” 反問句的 否定意義將在語言使用者心理上固化下來, 在語言社團中約定俗成化。

\section{關鍵詞}

“什麼” 反問句, 否定, 修辭三段論, 約定俗成 